\title{
Role of multimodal imaging in the preparation for surgery to correct left atrial myxoma
}

Flor Baeza Garzón ${ }^{1}$, Juan Alfonso Bonilla Arjona ${ }^{1}$, Mauro Andrés Di Silvestre Alonso ${ }^{1}$, Pablo César Prada Arrondo ${ }^{1}$, MARIA MANUELA IZQUIERDO ${ }^{1}$, Ignacio Laynez Cerdeña $^{1}$, AMELIA DUQUE ${ }^{1}$, BELEN MARI ${ }^{1}$, and Juan Lacalzada-Almeida ${ }^{1}$

${ }^{1}$ Hospital Universitario de Canarias

April 28, 2020

\begin{abstract}
Myxoma is the most frequent primary cardiac tumor. The treatment of choice is complete surgical resection. We present the case of a patient assessed for a long history of dyspnea on exertion. The patient was diagnosed with a large left atrial myxoma that obstructed the left ventricular inflow tract. Multimodal imaging played a key role in diagnosis, planning of surgery, and management of the complications arising from the condition.
\end{abstract}

\section{Hosted file}

Manuscrito Echoc_.doc available at https://authorea.com/users/314159/articles/444536-role-ofmultimodal-imaging-in-the-preparation-for-surgery-to-correct-left-atrial-myxoma
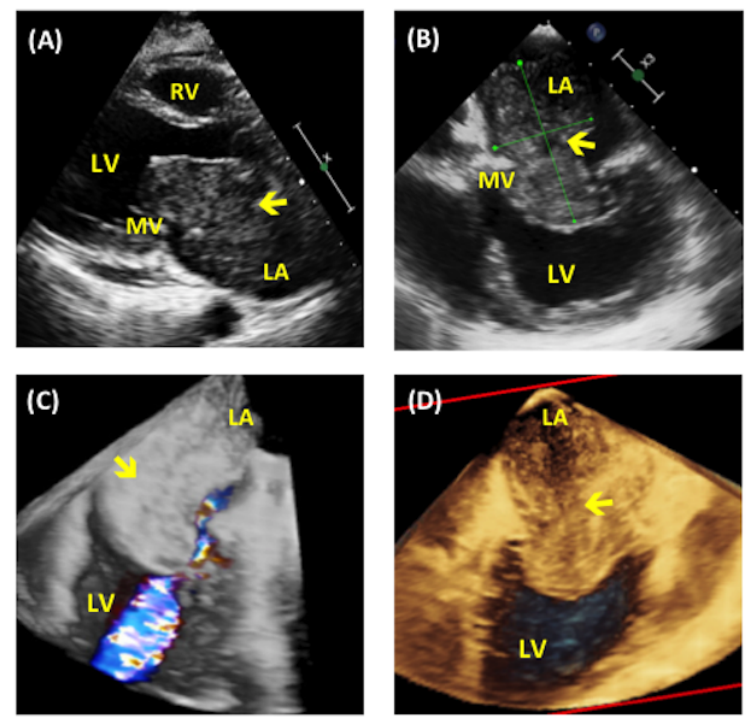

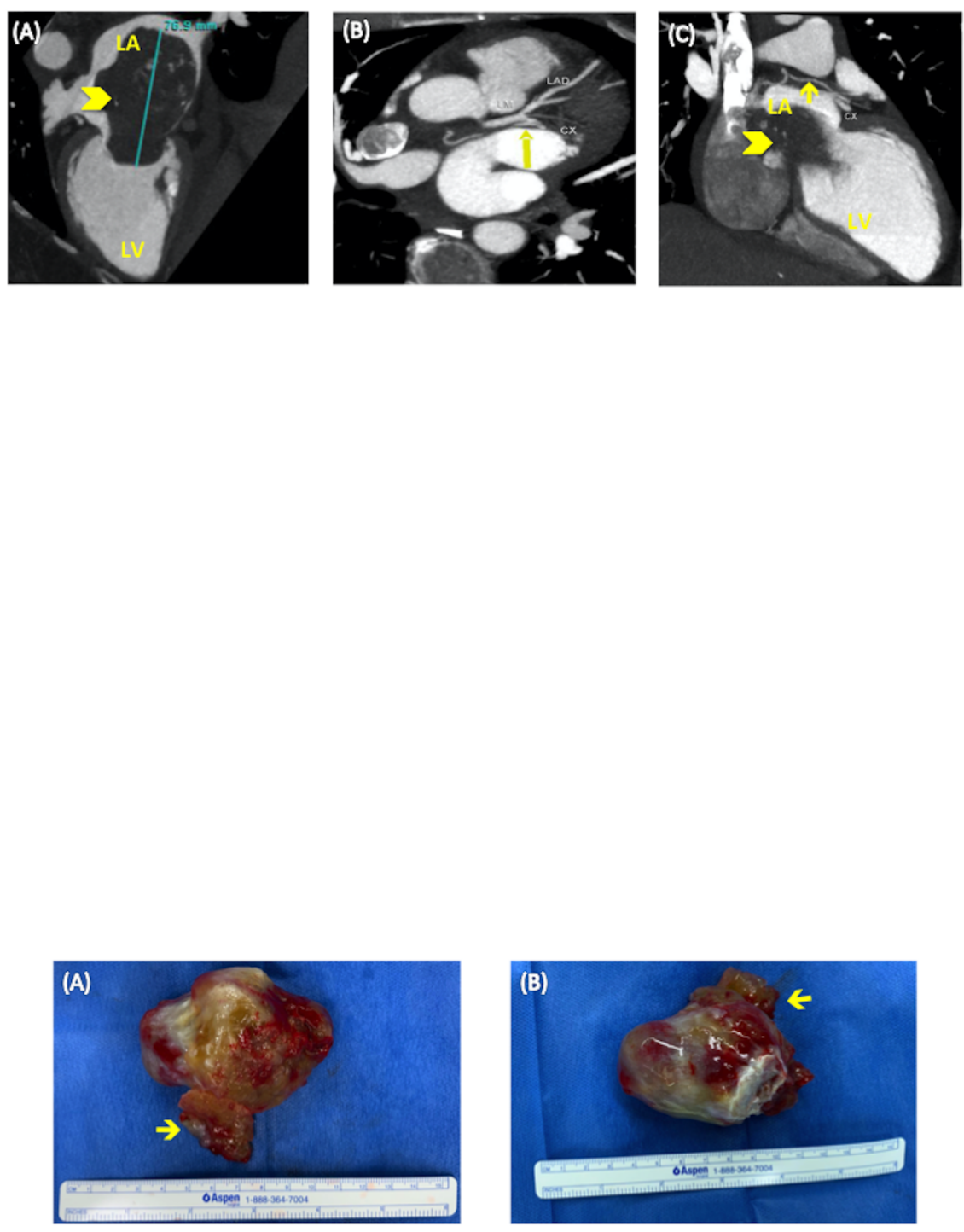

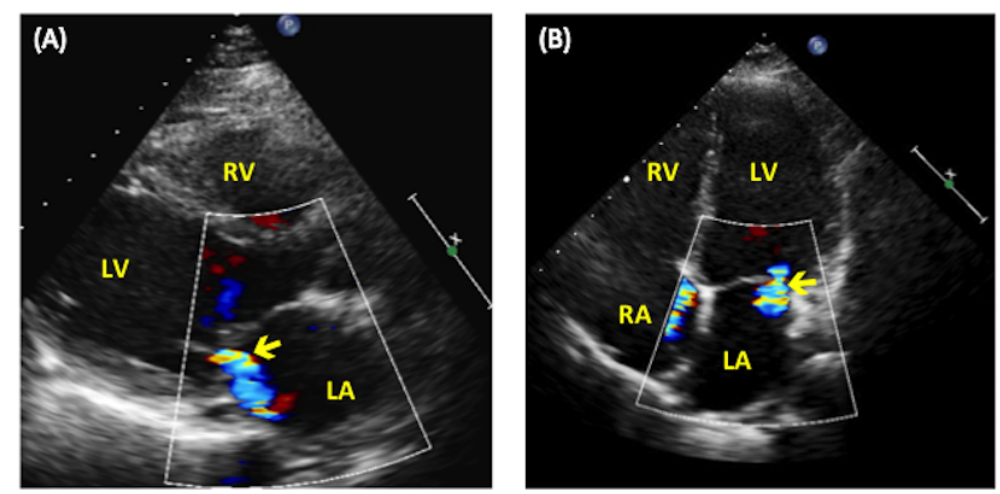